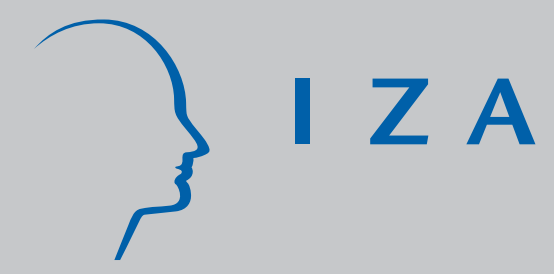

IZADP No. 2973

J ob Assignments under Moral Hazard:

The Peter Principle Revisited

Alexander K. Koch

J ulia Nafziger

August 2007 


\title{
Job Assignments under Moral Hazard: The Peter Principle Revisited
}

\author{
Alexander K. Koch \\ Royal Holloway, University of London \\ and IZA \\ Julia Nafziger \\ ECARES, Université Libre de Bruxelles
}

Discussion Paper No. 2973

August 2007

IZA

P.O. Box 7240
53072 Bonn
Germany

Phone: $+49-228-3894-0$

Fax: +49-228-3894-180

E-mail: iza@iza.org

\begin{abstract}
Any opinions expressed here are those of the author(s) and not those of the institute. Research disseminated by IZA may include views on policy, but the institute itself takes no institutional policy positions.

The Institute for the Study of Labor (IZA) in Bonn is a local and virtual international research center and a place of communication between science, politics and business. IZA is an independent nonprofit company supported by Deutsche Post World Net. The center is associated with the University of Bonn and offers a stimulating research environment through its research networks, research support, and visitors and doctoral programs. IZA engages in (i) original and internationally competitive research in all fields of labor economics, (ii) development of policy concepts, and (iii) dissemination of research results and concepts to the interested public.
\end{abstract}

IZA Discussion Papers often represent preliminary work and are circulated to encourage discussion. Citation of such a paper should account for its provisional character. A revised version may be available directly from the author. 
IZA Discussion Paper No. 2973

August 2007

\section{ABSTRACT}

\section{Job Assignments under Moral Hazard: The Peter Principle Revisited ${ }^{*}$}

The Peter Principle captures two stylized facts about hierarchies: first, promotions often place employees into jobs for which they are less well suited than for that previously held. Second, demotions are extremely rare. Why do organizations not correct 'wrong' promotion decision? This paper shows in a complete contracting setting that a simple trade-off between incentive provision and efficient job assignment may make it optimal to promote some employees to a job at which they produce less than they would at the previous level.

JEL Classification: D82, J31, J33, M12

Keywords: moral hazard, information, job assignments, Peter Principle

Corresponding author:

Alexander K. Koch

Royal Holloway, University of London

Dept. of Economics

Egham TW20 0EX

United Kingdom

E-mail: Alexander.Koch@rhul.ac.uk

\footnotetext{
We thank Mathias Dewatripont, Guido Friebel, Paul Heidhues, Ian Jewitt, Thomas Kittsteiner, Matthias Kräkel, and Urs Schweizer for helpful comments. The second author is grateful to Nuffield College, University of Oxford for its kind hospitality.
} 


\section{Introduction}

Organizations face the problem to match individuals with the job in which they are most productive and to provide them with incentives. In practice one observes that job assignments are often used to motivate employees - leading to an inefficient allocation of employees to jobs. This seems puzzling to economists: why do firms not separate the two roles and leave the provision of incentives to pay-for-performance schemes? We show in a simple moral hazard model that this is not possible, even if the principal and the agent can write a complete incentive contract: a static trade-off between incentive provision and efficient assignment leads to inefficient job assignments.

To develop this trade-off we employ a simple moral hazard model. A risk neutral principal needs to assign a risk neutral and wealth constrained agent to one of two jobs (a high ability and a low ability one). The probability that the agent succeeds in producing a high output depends in each job on his (known) ability and his effort (high or low). To derive further implications, we later extend the model to allow for continuous effort.

The optimal job assignment depends on the strength of two effects. On the one hand, the agent's ability determines in which of the two jobs his success probability is higher, say the low ability one. On the other hand, placing the agent in the high ability job reduces the cost of implementing a given effort level, if the output in this job is more informative about his effort than output in the low ability job: seeing a low ability agent succeed in the demanding high ability job indicates that he worked really hard. If the principal placed the agent instead in the low ability job, success would be quite likely even without effort. And this makes it costly to get the agent to work hard. Overall, for intermediate ability levels, the reduction in the cost of incentives outweighs the negative effect of a reduced success probability. This creates a distortion in the job assignment decision.

We discuss how these findings help understand inefficiencies in promotion policies. Promotions often place employees into jobs for which they are less well suited than for the previously held position. Nevertheless, demotions are rare in practice ${ }^{1}$ The former is not surprising - mistakes can happen. The latter, however, is puzzling: why do organizations not correct 'wrong' promotion decisions? Put differently, why do some employees rise to their "level of incompetence" and then remain at that hierarchy level, a phenomenon known as the Peter Principle (Peter and Hull 1969)? Our model can help explain this puzzle because job assignments are a crucial aspect of promotion policies. For agents who start their career in an entry level job, the principal at some point faces a decision whether or not to promote them to a job further up in the hierarchy that requires a higher ability level. This decision is thus similar to the static job assignment problem above.

\footnotetext{
${ }^{1}$ For references to empirical studies documenting this see Section 3
} 
And because jobs further up in the hierarchy are typically more informative about effort than lower hierarchy ones (e.g. Baker et al. 1994, Maskin et al. 2000, Ortega 2003), the model predicts that some individuals are promoted even though they would produce more if they remained in their previous job. Such a decision hence is not a mistake, but optimal: the promotion allows extracting more effort from the agent than he would be willing to provide for the same earnings in the lower level job. As a consequence, employees moving up the career ladder may earn more only because they have to work harder. Furthermore, our results help understand why a promotion is commonly viewed as a desirable career move but why, at the same time, not everyone who is promoted is as happy as he would be if he could stay in his old job (sometimes referred to as overpromotion). Most workers are better off with a promotion than without. But those at the bottom end of the ability distribution in the higher level job have to put in extra effort to outweigh their lack in talent. This makes them less happy than they would be if they could stay in their old job.

The paper is structured as follows. After discussing the related literature we introduce the static job assignment model in Section 2. Section 3 analyzes promotions and the Peter Principle. The final section discusses our findings and concludes. All proofs are in the appendix.

\section{Related Literature}

The large literature on careers and incentives in organizations emphasizes two roles of job assignment and promotion decisions. First, learning about the abilities of employees drives the allocation policy. Firms initially place individuals in jobs where they can do little harm. Those who prove to be able are then promoted to positions that require a higher level of ability. Second, promotions are a source of incentives.$^{2}$

This literature identifies several reasons for distortions in job assignments. The principal may want to distort job assignments to influence the information about employees' abilities she herself (e.g. Meyer 1991) or outsiders receive (e.g. Waldman 1984a, Ricart i Costa 1988, Bernhardt 1995), or what is revealed to an employee about his own ability (Ishida 2006, Nafziger 2007). If job assignment decisions need to be delegated, distortions may also arise because of the additional agency layer (Carmichael 1988, Baliga and Sjöström 2001, Fairburn and Malcomson 2001, Carrillo 2003, Friebel and Raith 2004).

\footnotetext{
${ }^{2}$ For an excellent survey of the literature see Gibbons and Waldman (1999a). Examples for the first strand are: Prescott and Visscher (1980), O'Flaherty and Siow (1992), and Valsecchi (2003); examples for the second strand are: Lazear and Rosen (1981), Malcomson (1984), Rosen (1986), and MacLeod and Malcomson (1988).
} 
When asking about the reasons for distortions in job assignments, the literature tries to address two puzzles. First, why can the role of matching individuals with jobs and that of providing incentives not be separated; leaving the former to job assignment decisions and the latter to pay-for-performance schemes (Baker et al. 1988)? Explanations for this are based on contractual imperfections: for example, performance is not verifiable (e.g. Malcomson 1984), or some aspects of performance - such as human capital accumulation - are not contractible (e.g. Prendergast 1993, Kwon 2006).

Second, why are demotions so rare - even though many employees turn out to be less productive in their job than they would be in their former position? Lazear (2004) offers an explanation for this so-called Peter Principle based on temporary shocks to productivity. A promotion means that a worker has delivered a high measurable output, which is the sum of permanent and transitory components. Because of regression to the mean of the temporary productivity shocks, output declines on average after a promotion. Bernhardt (1995) and Faria (2000) formalize an idea from Peter and Hull (1969): promotion is based on the performance in one task (say as a laborer), but the skills required in the new task (say as a manager) may be quite different. While on average a more able laborer is also likely to be a better manager, such a laborer may turn out to be a failure as a manager once promoted. If there is asymmetric information about employee abilities, the employer may however refrain from demotions because she has to pay a bonus to retain a demoted worker (Bernhardt 1995). Fairburn and Malcomson (2001) include incentive considerations, and assume that workers can sway the performance evaluation of their supervisors with bribes. This makes incentive pay ineffective for the principal: supervisors and their workers would simply collude to extract high wages without any effort in return. Making workers' pay contingent on their job, and managers' pay contingent on the firm's profits, aligns managers' interests more closely with those of the firm's owners: promoting a very untalented worker reduces profits, and thus reduces the supervisor's pay by more than what the supervisor could gain by extracting a bribe. Still, some workers close to the efficient promotion threshold are promoted even though they should not be.

Our approach is complementary to this. We start from assumptions that are most favorable to avoiding inefficiencies in promotion decisions: there is no uncertainty about the agent's ability and complete contracts are possible. We show that nevertheless a principal would not adopt an efficient job assignment policy. And she may promote some workers to a higher level task at which they are less productive than they would be in their previously held position. Our results thus contribute to understanding both puzzles referred to earlier: even with complete contracts job assignment and incentive provision need not be separable; and the absence of demotions may to some extent reflect that inefficient promotion decisions are optimal for the principal. 
From a theoretical point of view, our model is most closely related to Robbins and Sarath (1998). They show in a setting with a risk averse agent that the principal may not always want to choose the output system that generates the highest revenue. Different output systems vary in how informative they are about the agent's effort. While a more informative system has a lower implementation cost, it need not be the one that also creates a higher revenue. Output systems in their paper correspond in our setting to agents with different abilities in the two jobs. Our model with a risk neutral agent who is protected by limited liability allows us to look at a continuum of output systems, rather than only two systems as in Robbins and Sarath (1998). This enables us to show how inefficient job assignments may emerge even in a complete contracting setting, and how this can help understand the Peter Principle.

\section{The static job assignment model}

\subsection{The model}

A risk neutral principal ('she') needs to assign an agent ('he') to one of two jobs, $j \in$ $\{l, h\}$. He is protected by limited liability and has a reservation utility of zero. In each job he produces a verifiable and observable output. Output can either be high (revenue for the principal normalized to 1 ) - or low (revenue normalized to 0 ). The probability of high output, $f_{j}(e, \theta)$, depends on the job $j \in\{l, h\}$, the agent's ability $\theta \in[\underline{\theta}, \bar{\theta}]$, and his effort $e \in\{\underline{e}, \bar{e}\}$. We assume that $f(\cdot, \theta)$ is twice continuously differentiable in $\theta$ (subscript $\theta$ denotes the partial derivative with respect to $\theta$ ), and that higher effort leads to a higher success probability, i.e. $f_{j}(\bar{e}, \theta)>f_{j}(\underline{e}, \theta) \forall \theta$. The utility cost of effort is $c$ if the agent provides high effort and zero otherwise.

Job $l$ is the low ability job: it entails 'safe' tasks, where a low ability agent can do no harm because the success probability is insensitive to ability. Hence, we simplify notation to $f_{l}(e) \equiv f_{l}(e, \theta)$ hereafter. Job $h$ is the high ability job: expected output increases with higher ability, and the impact of ability on output also (weakly) increases with effort (i.e. ability and effort are weak complements). This is captured by the following sensitivity to ability (SA) assumption:

$$
0=f_{l \theta}(\underline{e}, \theta)=f_{l \theta}(\bar{e}, \theta)<f_{h \theta}(\underline{e}, \theta) \leq f_{h \theta}(\bar{e}, \theta) .
$$

Additionally, we assume that for a given effort, an agent with the highest ability level $(\bar{\theta})$ is most productive in job $h$, and an agent with the lowest ability level $(\underline{\theta})$ is most productive in job $l$. The following single crossing (SC) property expresses this formally:

$$
f_{h}(e, \underline{\theta})<f_{l}(e, \underline{\theta}) \text { and } f_{l}(e, \bar{\theta})<f_{h}(e, \bar{\theta}) \text { for } e \in\{\underline{e}, \bar{e}\} \text {. }
$$




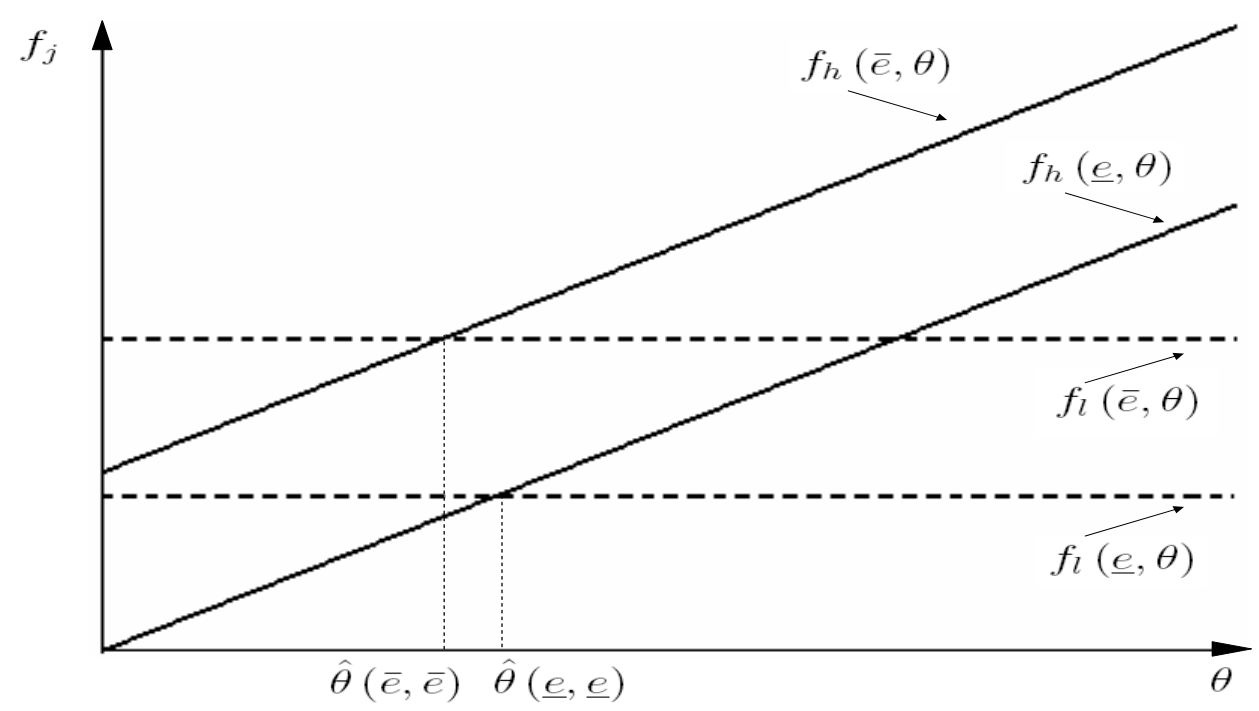

Figure 1: Single crossing property with equal efforts in the two jobs $\left[f_{h}(e, \theta)=q_{h}(e)+\theta, q_{h}(\bar{e})=0.4, q_{h}(\underline{e})=0 ; f_{l}(e)=q_{l}(e), q_{l}(\bar{e})=0.7, q_{l}(\underline{e})=0.35\right]$

Together with condition (SA) this implies that for $e \in\{\underline{e}, \bar{e}\}$ there exists a unique threshold $\hat{\theta}(e, e)$ such that all types with $\theta \geq \hat{\theta}(e, e)$ have a higher success probability in job $h$ than in job $l$, and all types with $\theta<\hat{\theta}(e, e)$ have a lower one. Figure 1 illustrates this, and also shows that the success probability functions for the two jobs need not cross for unequal effort levels. Thus, our single crossing property is weaker than the standard one, which would require the two functions to cross once for every pair of equal or unequal effort levels across jobs.

The timing is as follows. At the beginning of the period the principal offers a contract specifying the job $j \in\{l, h\}$ and an output-contingent wage scheme. The latter fixes a wage $\bar{w}_{j}$ after a high output and $\underline{w}_{j}$ after a low one. Both the principal and the agent know the agent's ability $\theta \in[\underline{\theta}, \bar{\theta}]$. If the agent accepts the contract, he provides unobservable effort $e \in\{\underline{e}, \bar{e}\}$. At the end of the period output and payoffs realize: the principal receives the revenue net of the wage to the agent; the agent receives utility equal to the wage less his effort cost. If the agent rejects the contract, the game ends with zero payoffs for all players.

\subsection{Observable effort (first best)}

As a benchmark, we first derive the job assignment rule for the case where the principal can observe the agent's effort. Here she simply compensates him for his effort cost, i.e. 
she pays him in each job a constant wage of $c$ if he works hard and zero otherwise. Thus, given job $j$ and type $\theta$ her expected profit is either $\Pi_{j}^{F B}(\bar{e}, \theta)=f_{j}(\bar{e}, \theta)-c$ for high effort or $\Pi_{j}^{F B}(\underline{e}, \theta)=f_{j}(\underline{e}, \theta)$ for low effort. To make the second-best problem interesting, we assume that first-best profits for high effort are larger than the ones for low effort:

Assumption 1 High effort is efficient in both jobs, i.e.

$$
f_{j}(\bar{e}, \theta)-f_{j}(\underline{e}, \theta)>c, \quad j=l, h, \quad \forall \theta \in[\underline{\theta}, \bar{\theta}] .
$$

What is the optimal job assignment rule given Assumption 11? The principal places an agent with type $\theta$ to job $h$ if and only if the maximized profit in job $h$ is higher than in job $l$. Because implementing high effort $\operatorname{costs} c$ in both jobs, this is the case if and only if $f_{h}(\bar{e}, \theta) \geq f_{l}(\bar{e})$. This shows that the first-best job assignment rule places the agent in the job where he is most productive: job $h$ if $\theta \geq \theta^{F B}=\hat{\theta}(\bar{e}, \bar{e})$ and job $l$ otherwise.

\subsection{Unobservable effort (second best)}

This section analyzes the main model, where the principal cannot observe the effort choice of the agent. The problem she faces is now not only to assign the agent to a job, but also to design an appropriate incentive scheme that makes it optimal for the agent to provide the effort she desires. To solve this, we apply for each job separately the usual two-step procedure for moral hazard problems. First, for a given effort level $e$, we find the cost minimizing wage scheme that implements $e$ in job $j$. Second, given these wage schemes, we maximize profits with respect to effort. In a third step we then determine the profit maximizing job assignment rule.

\subsubsection{The incentive scheme}

Consider the first part of the problem. If the principal wants to implement high effort, she minimizes the expected wage bill

$$
f_{j}(\bar{e}, \theta) \bar{w}_{j}+\left[1-f_{j}(\bar{e}, \theta)\right] \underline{w}_{j},
$$

taking into account that $\underline{w}_{j}, \bar{w}_{j} \geq 0$ (the limited liability constraint), that the agent's expected utility must be larger than his reservation utility of zero (the participation constraint) and that it must be optimal for him to provide high effort. The latter is the case if the following incentive constraint is satisfied:

$$
\left[f_{j}(\bar{e}, \theta)-f_{j}(\underline{e}, \theta)\right]\left(\bar{w}_{j}-\underline{w}_{j}\right) \geq c
$$

Because of limited liability the agent can guarantee at least his reservation utility of zero simply by providing low effort. Thus, the participation constraint does not bind and 
the wage after a failure is zero. The wage after a success is set to make the incentive constraint bind: $\bar{w}_{j}=\frac{c}{f_{j}(\bar{e}, \theta)-f_{j}(\underline{e}, \theta)}$. Hence, the principal can only get the agent to exert effort by leaving him a rent in addition to compensating him for the effort cost $c$. The expected profit from assigning an agent with type $\theta$ to job $j$ and implementing high effort thus is

$$
\Pi_{j}^{S B}(\bar{e}, \theta)=f_{j}(\bar{e}, \theta)-C_{j}(\bar{e}, \theta), \quad C_{j}(\bar{e}, \theta)=\frac{f_{j}(\bar{e}, \theta)}{f_{j}(\bar{e}, \theta)-f_{j}(\underline{e}, \theta)} c
$$

where $C_{j}(\bar{e}, \theta)$ is the expected wage payment, to which we refer in the following as the implementation cost.

As we have seen above, a spread between the wage after success and failure is needed to make the agent work hard. If these wages are equal the agent always provides low effort. Thus, to implement $\underline{e}$ the principal sets $\underline{w}_{j}=\bar{w}_{j}=0$, resulting in expected profit $\Pi_{j}^{S B}(\underline{e}, \theta)=f_{j}(\underline{e}, \theta)$.

We can now consider the second part of the principal's problem. It is optimal to implement high effort in job $j$ if and only if $\Pi_{j}^{S B}(\bar{e}, \theta) \geq \Pi_{j}^{S B}(\underline{e}, \theta)$. Rearranging gives the following condition:

$$
\left[f_{j}(\bar{e}, \theta)-f_{j}(\underline{e}, \theta)\right]^{2} \geq f_{j}(\bar{e}, \theta) c .
$$

(Condition 1)

If this fails to hold the principal distorts downward the implemented effort to save on implementation costs. As the job assignment rule is sensitive to effort, it would not be surprising if such a distortion lead to inefficient assignments. For the moment we therefore want to focus on the case where no such distortion of effort occurs, i.e. Condition 1 is satisfied for both jobs and for all types $\theta \in[\underline{\theta}, \bar{\theta}]$. This enables us to show that inefficiencies in the job assignment rule under moral hazard are not an artefact of inefficient effort choices.

\subsubsection{Job assignments given high effort in both jobs}

In this section we characterize the job assignment rule that the principal adopts if she wants to implement high effort in both jobs. We can describe this rule by ability level(s) $\theta^{S B}$ for which $\Pi_{h}^{S B}\left(\bar{e}, \theta^{S B}\right)-\Pi_{l}^{S B}(\bar{e})=0$ holds. To characterize these threshold(s) further, we first have to look more closely at the behavior of the profit functions (and their difference) in $\theta$. While for job $l$ this is clear - profits do not depend on $\theta$ - there are two potentially opposing effects in job $h$. On the one hand, a higher $\theta$ increases the expected output, but on the other hand, there may be a negative effect on implementation costs. The following lemma shows that the first effect always dominates, and thus profits in job $h$ and the difference in profits across jobs increase with the agent's ability: 
Lemma 1 Suppose Condition 1 holds for $\theta \in[\underline{\theta}, \bar{\theta}]$, then

(a) $\frac{d}{d \theta} \Pi_{h}^{S B}(\bar{e}, \theta)>0$,

(b) $\frac{d}{d \theta}\left[\Pi_{h}^{S B}(\bar{e}, \theta)-\Pi_{l}^{S B}(e, \theta)\right]>0$ for $e \in\{\underline{e}, \bar{e}\}$.

From Lemma 1 it follows that there is a unique threshold $\theta^{S B}$. Now, is $\theta^{S B}$ lower or higher than the first-best threshold $\theta^{F B}$ ? This relies on whether $\Pi_{h}^{S B}\left(\bar{e}, \theta^{F B}\right)-\Pi_{l}^{S B}(\bar{e})$ is positive or negative. In contrast to the first-best setting, the profit difference depends not only on the difference in expected revenues, but also on the effect that the job assignment has on the cost of implementing high effort. Consider first the expected revenue part. At ability level $\theta^{F B}=\hat{\theta}(\bar{e}, \bar{e})$ the job assignment does not change the expected revenue, because the agent is equally productive in both jobs if he works hard. Hence, the above profit difference is simply the difference in implementation costs. Using Equation (3), it follows that the implementation costs are lower when assigning an agent with ability $\theta^{F B}$ to job $h$ rather than to job $l$ if and only if $f_{h}\left(\underline{e}, \theta^{F B}\right)<f_{l}(\underline{e})$. Under this condition, high effort in job $h$ raises the success probability of the project more than in job $l: f_{h}\left(\bar{e}, \theta^{F B}\right)-f_{h}\left(\underline{e}, \theta^{F B}\right)>f_{l}(\bar{e})-f_{l}(\underline{e})$, because $f_{l}(\bar{e})=f_{h}\left(\bar{e}, \theta^{F B}\right)$. Thus, a relatively low ability agent who wanted to shirk would have a harder time hiding this in job $h$ than in the low ability job $l$. In that sense, the principal can put such an agent to a harder test by placing him in the more demanding job $h$ : success in the high ability job is a sign that he must have worked really hard. And this makes it is less costly to provide incentives in job $h$.

Stated differently, the principal can be more confident that the agent worked hard, and did not just rely on his good fortune, when success is the outcome of a 'hard' test rather than that of an 'easy' test. To see this more formally, note that the condition $f_{h}\left(\underline{e}, \theta^{F B}\right)<f_{l}(\underline{e})$ implies the following relation of likelihood ratios:

$$
\frac{f_{h}\left(\bar{e}, \theta^{F B}\right)}{f_{h}\left(\underline{e}, \theta^{F B}\right)}>\frac{f_{l}(\bar{e})}{f_{l}(\underline{e})} .
$$

Each ratio reflects how likely it is after observing high output in a particular job that the agent provided effort $\bar{e}$ instead of $\underline{e}$. According to Equation (4) it is more likely in job $h$ than $l$ that high output of an agent with ability $\theta^{F B}$ was the result of hard work. As Demougin and Fluet (1998) show, such a comparison of likelihood ratios in the high output state is an appropriate criterion for ranking different information systems for risk neutral agents that are protected by limited liability. And thus - because an information system corresponds here to a type-job combination - Equation (4) translates to job $h$ being more informative about effort than job $l$ for an agent with ability $\left.\theta^{F B}\right]^{3}$

\footnotetext{
${ }^{3}$ Note that this definition of informativeness differs slightly from those proposed for the case of risk averse agents with unlimited liability, where the whole likelihood ratio distribution matters (Grossman
} 
We summarize in the following proposition:

Proposition 1 Suppose Condition 1 holds for jobs $j=l, h$ and $\theta \in[\underline{\theta}, \bar{\theta}]$. Then $\theta^{S B}<\theta^{F B}=\hat{\theta}(\bar{e}, \bar{e})$ if and only if

$$
f_{h}(\underline{e}, \hat{\theta}(\bar{e}, \bar{e}))<f_{l}(\underline{e})
$$

where $\theta^{S B}$ and $\theta^{F B}$ are the thresholds for assignment to the high ability job $h$ in the principal's second-and first-best job assignment rules, respectively.

The result is not driven by the well known downward distortion of effort that can arise in moral hazard problems: in the setting above, job assignments are inefficient even though the principal implements the efficient effort level in all of the jobs. The next section turns to job assignments when there are distortions in effort levels.

\subsubsection{Job assignments given distorted effort levels}

This section discusses the additional effects that a distortion of effort has on the job assignment rule. To illustrate these we assume that Condition 1 is always violated for job $l$, so $e_{l}^{S B}=\underline{e}$. Moreover, we assume that Condition 2 holds.

Suppose first that in job $h$ Condition 1 is also violated for all ability levels. As the principal implements low effort in both jobs, no incentives are needed. Thus, the job assignment problem reduces to maximizing the expected revenue $f_{j}(\underline{e}, \theta)$, resulting in threshold $\theta^{S B}=\hat{\theta}(\underline{e}, \underline{e})>\theta^{F B}=\hat{\theta}(\bar{e}, \bar{e})$. The downward distortion of effort pushes the threshold for assignment to the high ability job above the first-best level. This is the exact opposite of the case considered in Section 2.3.2, where no distortion of effort occurs in either job. There the assignment to job $h$ leads to an implementation cost saving effect that pulls the threshold below the first-best level.

For intermediate cases, both forces are at work. Suppose now that for job $h$ Condition 1 holds for all $\theta 4^{4}$ As no incentives are needed in job $l$, placing the agent into job $h$ cannot lead to cost savings. But it is cheaper to implement high effort in job $h$ than it would be in job $l$. Hence, assigning the agent to job $h$ and then implementing high effort might be worthwhile. For this reason the job assignment threshold $\theta^{S B}$ may be lower than $\hat{\theta}(\underline{e}, \underline{e})$. In sum, $\theta^{S B}$ lies between the job assignment threshold from Proposition 1 and $\hat{\theta}(\underline{e}, \underline{e})$.

Is it still possible that $\theta^{S B}$ is lower than $\theta^{F B}$ ? The only reason for placing an agent into job $h$ - even though he would be more productive in the low ability job $l$ - is to

and Hart 1983, Kim 1995, Jewitt 2006). The difference stems from the fact that for risk neutral agents there is no cost of concentrating rewards in one state. Because the wage after low output is zero, there is no need to 'estimate' the agent's effort in the failure state.

${ }^{4}$ Dropping the qualifier "for all $\theta$ ", implies that multiple thresholds are possible. Then $\theta^{S B}$ in the results below is the lowest threshold for assigning the agent to job $h$ (see the proof in the appendix). 
implement high effort. When does this pay off for the principal? Assigning the agent to the higher level job and implementing high effort increases output by $f_{h}(\bar{e}, \theta)-f_{l}(\underline{e})$. This has to outweigh the increase in wage costs of $C_{h}(\bar{e}, \theta)$. Hence, if there is a strict gain in profit from assigning an agent with ability $\theta^{F B}$ to job $h$, we know that $\theta^{S B}<\theta^{F B}$. This is summarized in the next proposition:

Proposition 2 Suppose Condition 1 is violated for job $l$ and Condition 2 holds. Then, (a) $\theta^{S B} \leq \hat{\theta}(\underline{e}, \underline{e})$, and $\theta^{S B}$ is higher than it would be if $e_{1}^{S B}(\theta)=e_{2}^{S B}=e_{H} \forall \theta$;

(b) $\theta^{S B}<\theta^{F B}$ if and only if

$$
f_{h}\left(\bar{e}, \theta^{F B}\right)-f_{l}(\underline{e})>C_{h}\left(\bar{e}, \theta^{F B}\right) .
$$

(Condition 3)

\section{Promotions and the Peter Principle}

As job assignments are a crucial aspect of promotions in organizations, our previous results can help understand a puzzling empirical regularity related to promotion decisions: the Peter Principle. Even though employees are often placed in jobs for which they are less well suited than for their previously held position, demotions are rare. For example, Baker et al. (1994a, 1994b), Gibbs and Hendricks (2004), Treble et al. (2001) and Lin (2005) find demotion rates of less than 1 percent; and Chiappori et al. (1999) do not even observe a single demotion in their study covering 15 years of data from a large French state-owned firm..$^{5}$ The purpose of this section is to show that the static trade-off from the job assignment model offers a simple explanation for why firms only rarely correct what appears at first glance to be a botched promotion: an organization may deliberately place an employee into a job for which he is less talented than for the lower hierarchy level one.

\subsection{Applying the model to promotion decisions}

Promotion policies have two components. First, a static one that says how the firm assigns agents in a given period to lower and higher level jobs in the hierarchy. Second, a dynamic component that governs how job assignments vary over time for a given agent. We will first describe how our setup can capture properties of different jobs in a hierarchy, and then argue how to give the model a dynamic interpretation. We deliberately do not add additional dynamic trade-offs to the model. This makes clear that the Peter Principle may arise even if the principal has no desire to manipulate the agent's first-period incentives.

\footnotetext{
${ }^{5}$ An exception are the high demotion rates reported in Seltzer and Merrett's (2000) study of the 19th century Union Bank of Australia.
} 


\subsubsection{Properties of jobs in a hierarchy}

Typically, jobs further up in the hierarchy of an organization require a high ability. Less able individuals should be employed in lower level jobs, where the consequences of their actions are less severe (e.g. Calvo and Wellisz 1979, Rosen 1982, Waldman 1984b). Properties that jobs $h$ and $l$ satisfy. Moreover, empirical evidence suggests that higher level jobs are likely to be more informative about an employee's effort (Maskin et al. 2000, Ortega 2003). Baker et al. (1994, p. 1127) provide a succinct illustration of this notion: " [...] market-adjusted stock-price performance may be a useful measure of a CEO's contribution but typically is an extremely noisy measure of the contributions of lower-level employees." In our model this is in line with Condition 2, which states that job $h$ is locally more informative than job $l$.

\subsubsection{The dynamic component}

Promotion policies govern how job assignments vary over time for a given agent. Our model can be given such a dynamic interpretation by adding a first period and the two features described in the following. Workers do not start their careers at the top of the hierarchy: job $l$ is the entry level job in the two-period model (Feature 1). Distortions in the promotion decision arise in our model because the principal wants to change the agent's incentives in the second period; first-period incentives do not drive results. This point can be made most clearly in a setting where the agent simply earns a fixed wage in the first work period. We therefore assume that an unexperienced agent's effort does not increase revenue much, so that the principal simply implements low effort in the first work period (Feature 2). Letting $g_{j}$ denote the success probability function for an unexperienced agent in job $j$, Feature 2 can be captured by having $g_{j}(\underline{e}, \theta)=g_{j}(\bar{e}, \theta)$. Feature 1 can be modeled by assuming that the agent's ability is initially unknown and that its expected value is sufficiently low so that he should start in the low ability job: $g_{l}(e) \geq E\left[g_{h}(\underline{e}, \theta)\right]$. During the first period the agent's ability is revealed to the principal and the agent, so the promotion decision in the second work period mirrors the static job assignment problem from Section 2. The second-period success probability $f_{j}(e, \theta)$ differs from the first-period success probability because of learning by doing.

\subsection{The Peter Principle}

The Peter Principle says that some employees are promoted to their "level of incompetence" and then remain at that hierarchy level (Peter and Hull 1969). It refers to

\footnotetext{
${ }^{6}$ For example, $E[\theta]<\hat{\theta}^{g}(\underline{e}, \underline{e})$ and $g_{h \theta \theta}(\underline{e}, \theta) \leq 0$ would be sufficient for this, where $\hat{\theta}^{g}(\underline{e}, \underline{e})$ is the crossing point of the expected output functions: $g_{l}(\underline{e})=g_{h}\left(\underline{e}, \hat{\theta}^{g}(\underline{e}, \underline{e})\right)$.
} 
cases where the agent produces less after promotion to a higher level job than if he were reassigned to the former job. Simply comparing actual expected outputs would be misleading, however: output could simply rise because the agent works more - hiding the fact that he is untalented for his new job. In our context we therefore compare outputs at the same effort level, and adopt the following definition 7

Definition 1 The Peter Principle holds for an agent with ability $\theta$ who is promoted to job $h$, in which he exerts effort $e$, if $f_{h}(e, \theta)<f_{l}(e, \theta)$.

To give conditions for the Peter Principle to hold we can draw on our earlier analysis.

\section{Corollary 1}

1. Suppose Condition 1 holds for $j=l, h, \forall \theta \in[\underline{\theta}, \bar{\theta}]$, and Condition 2 is satisfied. Then, the Peter Principle is valid for those at the bottom of the ability range in job $h$ : an agent with ability $\theta \in\left[\theta^{S B}, \theta^{F B}\right)$ is promoted to job $h$ even though $f_{h}(\bar{e}, \theta)<f_{l}(\bar{e})$.

2. Suppose that Condition 1 fails to hold for job l (i.e. $e_{l}^{S B}=\underline{e}$ ) and Condition 2 is satisfied.

(a) The Peter Principle arises for $\theta \in\left[\theta^{S B}, \theta^{F B}\right)$ if and only if Condition 3 holds.

(b) If Condition 3 is not satisfied, the Peter Principle does not arise for any $\theta \in[\underline{\theta}, \bar{\theta}]$.

Part 1 shows that the Peter Principle may hold for an agent placed in job $h$, even though the principal is perfectly aware of the fact that he would produce a higher expected output in the lower level job $l$. Promoting somebody "to his level of incompetence" thus is an optimal policy for the principal and not a mistake. Part 2 shows that the Peter Principle can arise also when there is a distortion of effort. How can the principal then gain from promoting an agent "to his level of incompetence"? While in job $l$ it is too expensive to get the agent to work hard, placing him in the higher level job $h$ may make this worthwhile, as output is more informative about effort. Only if the lower implementation cost for high effort cannot outweigh the agent's lack in talent, the Peter Principle does not arise. But a 'reverse' Peter Principle does not arise either, even in this case where the promotion threshold is above the first-best level $\theta^{F B}$ : the agent is more productive in the lower level job than he would be if placed in the higher level job and also putting in low effort only.

\footnotetext{
${ }^{7}$ Our definition refines that used in the literature, as extant models do not capture the possibility of the agent working harder than he would if he were reassigned to the previous job.
} 


\subsection{Empirical implications}

As we have shown above, what matters for the job assignment is how informative the different jobs in the hierarchy are about the effort of an agent. This tells the principal how she should assign the agent to get him to provide a given effort level at lowest cost. The principal may, however, not want to implement the same effort level in both jobs. We saw that in this case a promotion may get the agent to put in more effort than if he were simply reassigned to the previous job. Our two-effort model allowed understanding separately these effects of informativeness and distortions in effort choices. This, however, came at the cost of not having much flexibility in varying effort levels in and across jobs: the agent either provides the same effort in both jobs, or high effort in one and low effort in the other. The purpose of this section is to move beyond the two-effort setting and derive broader empirical implications. Doing so requires choosing a specific functional form to obtain closed form solutions for the optimal effort levels. We adopt the following specification: $f_{l}(e, \theta)=\alpha e, f_{h}(e, \theta)=\max \{\alpha e \theta-k, 0\}$ and $c(e)=e^{2} / 2$, with the parameter bounds given in Appendix $B$ to ensure internal solutions. ${ }^{8}$

The 'warm up' cost $k \geq 0$ for the more complex job $h$ allows varying the difference in informativeness of output across jobs. Analogous to the two-effort case, the continuous version of the likelihood ratio captures how informative output in job $j \in\{l, h\}$ is about effort: $r_{j}(e, \theta)=\frac{\frac{\partial}{\partial e} f_{j}(e, \theta)}{f_{j}(e, \theta)}$. In our setup, the inverse likelihood ratios across jobs have a simple relation: $\frac{1}{r_{h}(e, \theta)}=\frac{1}{r_{l}(e, \theta)}-\frac{k}{\alpha \theta}$. So at $k=0$ both jobs are equally informative about effort. With increasing $k$, job $h$ becomes more informative about effort relative to job l. Similarly, a higher ability in job $h$ implies that the output becomes less informative. The intuition is that a very able agent might succeed even without providing much effort compared to a less able agent in the same job.

\subsubsection{Optimal effort levels and promotion thresholds}

We first discuss the properties of the optimal effort levels. The first-best effort levels are given by $e_{l}^{F B}=\alpha$ and $e_{h}^{F B}(\theta)=\alpha \theta$. In each job we observe the usual downward distortion of effort. The second-best effort level in job $l$ is half of the first-best one: $e_{l}^{S B}=0.5 e_{l}^{F B}$. Comparing this to job $h$, where $e_{h}^{S B}(\theta)=0.5\left(e_{h}^{F B}(\theta)+\frac{k}{\alpha \theta}\right)$, one sees that the distortion relative to the first-best level is smaller than in job $l$, and decreases with a more informative output (higher $k$ ). For $k=0$ the relative distortion of effort is equal for both jobs.

Knowing the optimal effort levels allows us to derive the optimal promotion thresholds. These are given by $\theta^{F B} \equiv \sqrt{1+8 k}$ and $\theta^{S B} \equiv \frac{1+\sqrt{1+16 k}}{2}$, respectively. Again it is

\footnotetext{
${ }^{8}$ We focus here on the implications of the model as well as the links to previous results, and relegate derivations to Appendix B
} 


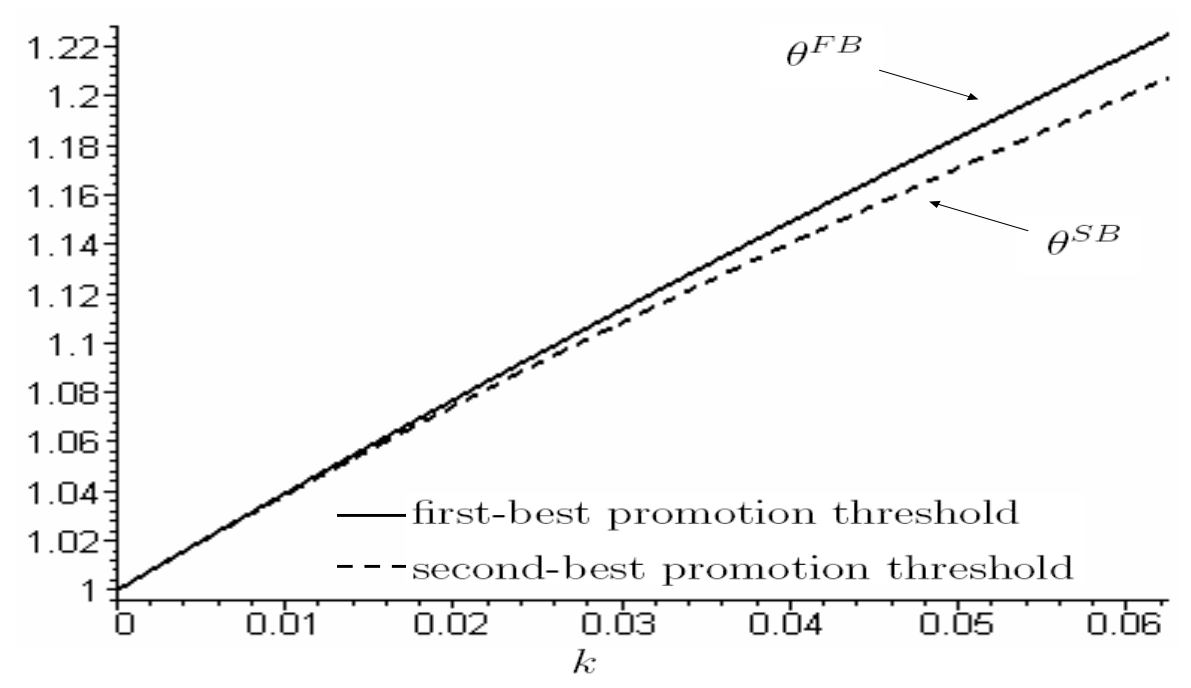

Figure 2: Second-best versus efficient promotion threshold

interesting to see how the difference between first- and second-best thresholds varies with the informativeness parameter $k$. For $k=0$ the second-best promotion threshold is efficient: as both jobs are equally informative about effort there is no relative distortion of effort. Hence, the principal cannot gain by moving away from the efficient promotion threshold. This is similar to the case in the two-effort model where the agent works hard in both jobs (effort is constant across jobs) and likelihood ratios are equal (both jobs are equally informative). Once the jobs differ in how informative about effort they are, the picture changes: for $k>0$ we have $\theta^{S B}<\theta^{F B}$. Figure 2 illustrates this. The gap between first- and second-best promotion thresholds increases in $k$. The greater $k$, the greater the relative distortion of effort levels across jobs, and thus the greater the distortion in the job assignment.

\subsubsection{Expected output and the Peter Principle}

What happens to expected output? Figure 3 shows that an agent promoted to the higher level job produces more than an agent who remains in job $l$. This however stems from the fact that the agent is made to work harder in job $h$ than he would work if he were assigned instead to job $l$ : comparing the output in job $h$ with the output the agent would produce in job $l$ when providing the same effort, shows that the Peter Principle emerges (see Figure 4). For ability levels close to the threshold $\theta^{S B}$, the agent would be more productive with his effort if he remained in job $l$ instead of being promoted to job $h$. 


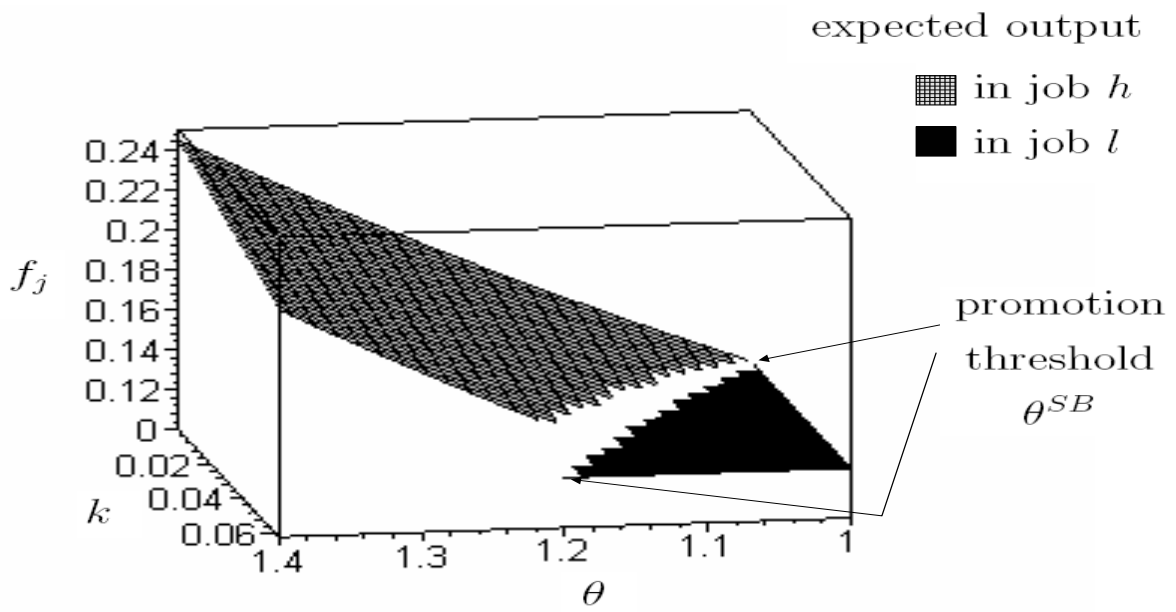

Figure 3: Expected output

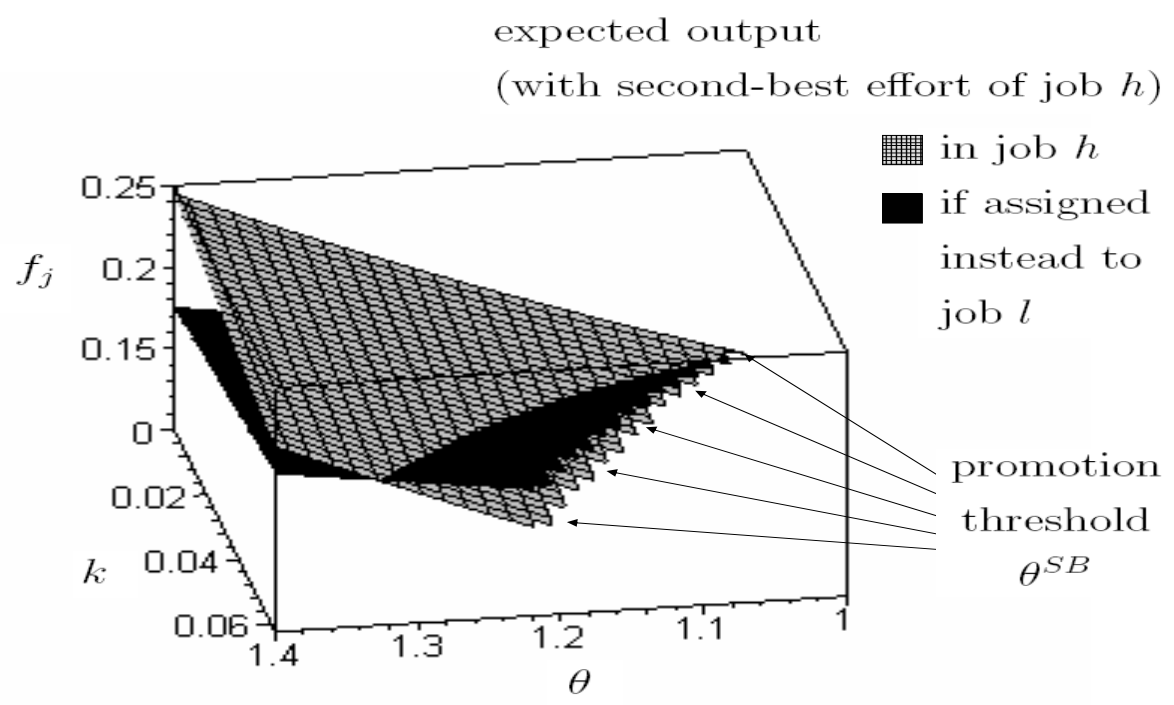

Figure 4: The Peter Principle 


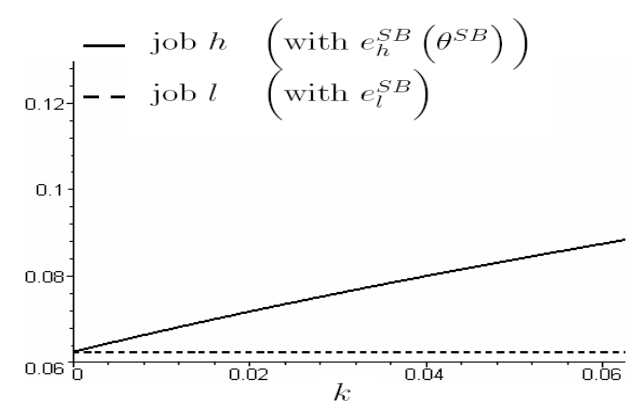

expected wage

with second-best effort

level of respective job

(a)

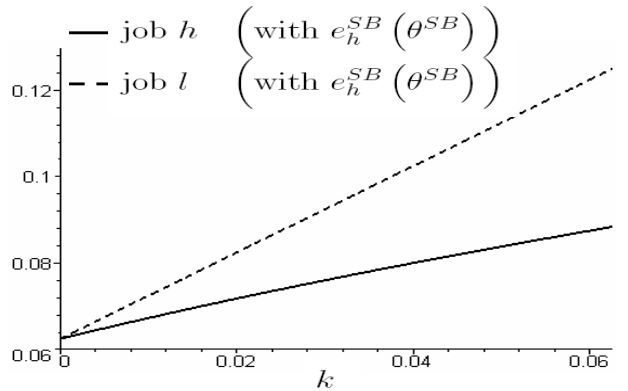

expected wage

with second-best effort

level of job $h$

(b)

Figure 5: Expected earnings and cost saving effect $\left(\theta=\theta^{S B}\right)$

What drives the Peter Principle are the two effects that we encountered earlier. First, because output in the higher level job is more informative about the agent's effort, the principal can save on costs for implementing a given level of effort by lowering the promotion threshold relative to the first-best one (similar to the case in the two-effort model where the principal implements high effort in both jobs).

Second, these savings allow the principal to get the agent to exert extra effort, which drives up expected output despite the Peter Principle (similar to the case in the twoeffort model where the principal implements low effort in job $l$ and high effort in job $h$ ). Figure 5 illustrates the cost saving effect. Panel (a) shows that an agent who is just at the promotion threshold (ability equal to $\theta^{S B}$ ) earns more than he would if he remained in the lower level job - and the difference widens the more informative job $h$ is relative to job $l$ (higher $k$ ). If however the principal wanted to have the agent work as hard in the lower level job as he does in the new job $h$, she would need to pay him much more, as shown in Panel (b).

\subsubsection{The profile of expected earnings and the agent's well being}

A more able agent can expect to earn more than a less able colleague, both within the higher level job and across jobs (see Panel (a) of Figure 6). As higher earnings are the result of harder work, the agent, however, is not necessarily happier than he would be if he could remain in his old job: Panel (b) of Figure 6 shows that for ability levels close to the promotion threshold, an agent promoted to job $h$ enjoys lower rents than he would in job $l$. The expected utility then increases with higher $\theta$ and soon exceeds that from 


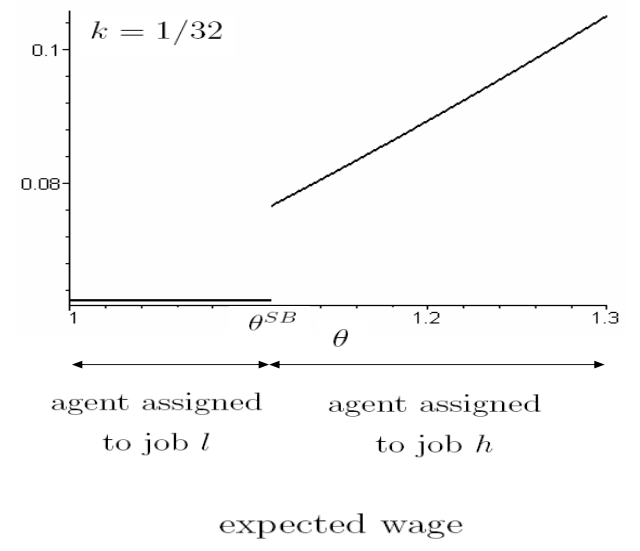

(a)

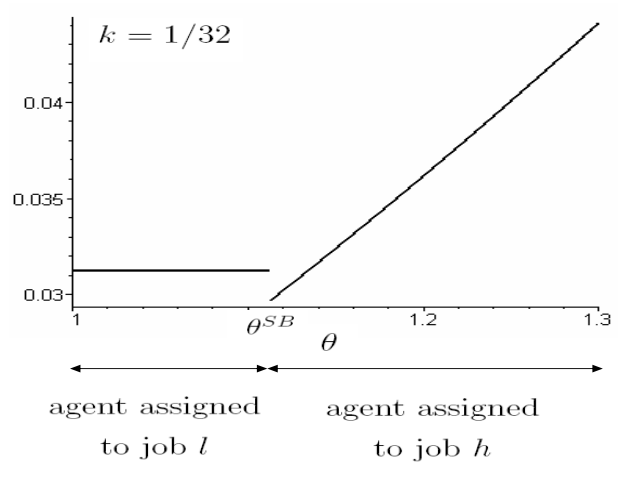

expected utility

(b)

Figure 6: Expected wage and expected utility $(k=1 / 32)$

working in the lower level job.

This is in line with the commonly expressed view that a promotion is a desirable career move: expected utility increases for most ability levels in job $h$. But the model also offers an explanation for why not everyone who is promoted is as happy as he would be if he could stay in his old job. Those at the bottom end of the earnings distribution in the higher level job are kept on toes because they are not sufficiently talented for the new position: to make up for their (slight) lack in talent they have to work harder than they would in their old job for the same expected earnings. Indeed, "overpromotion" has been identified as one of the factors causing stress at the workplace (e.g. Cooper and Marshall 1976, Murphy 1995) $!^{9}$

\section{Discussion and concluding remarks}

Our model with complete contracts showed that an organization may find it optimal to promote an employee even if this leads to a reduction in output (the Peter Principle). It thus provides a simple explanation for why firms only rarely correct what appears at first glance to be a botched promotion: an organization may deliberately place an employee into a job for which he is less talented than for the lower hierarchy level one. The reason is simple. Such a promotion decision makes it cheaper to induce hard work:

\footnotetext{
${ }^{9} \mathrm{~A}$ person is overpromoted when he "has reached the peak of his abilities with little possibility of further development and is given responsibility exceeding his capacity" (Cooper and Marshall 1976, p.18)
} 
facing a more challenging job, the employee has to make up for his lack in talent by exerting more effort than he would in his old job for the same compensation. In other words, the promotion policy complements the wage policy as a tool to reduce the rents that employees enjoy because of moral hazard problems in the organization.

The mechanism at work is essentially a static one: the job assignment decision in one period affects the contemporaneous cost of providing incentives. This alone is sufficient to create inefficiencies in the assignment policy. To not obscure this, we deliberately kept the promotion model simple. Nevertheless, the predictions are in line with several stylized facts. First, they offer an explanation for the empirical puzzle why organizations appear not to reverse promotion decisions, even when the employee is less productive than he would be in the former job. Second, it shows that employees moving up the career ladder may earn more only because they have to work harder than they would in their old jobs for the same pay - something that has not been modeled before, to our knowledge. Third, the setup shows that a promotion can be a good thing for most workers, but at the same time reduce the rents enjoyed by the least able workers in a hierarchy level. Because the latter have to put in extra effort to outweigh their lack in talent, they are less happy than they would be if they could stay in their old job - a phenomenon that the literature on workplace stress refers to as "overpromotion" (e.g. Cooper and Marshall 1976, Murphy 1995). One may wonder why people do not refuse to be overpromoted. But turning down a promotion may be difficult and costly. For example, the US Federal Circuit recently upheld the dismissal of a general attorney in the Los Angeles office of the Small Business Administration for rejecting a promotion ${ }^{10}$ Even when the penalties are less severe, people may accept their role for reasons of prestige, as illustrated by the following case: "a man in his early fifties had been overpromoted, but held on to his job because, as he put it, "of the status and authority of the role"' (Erskine and Brook 1971, p.55). Enriching the model with such concerns for status (see e.g. the model of Auriol and Renault 2007) seems to be an interesting direction for future research.

Clearly, there are many facets of careers in organizations that our simple model does not capture - indeed no single promotion model does a fully satisfactory job at this. In the spirit of Gibbons and Waldman's (1999b, 2006) integrated models, our framework can be enriched with other elements that help explain additional features of careers in organizations. For example, the effective ability of an agent may vary with tenure $t$ in the organization: $\rho_{t}(\theta)$. Or the expected output in a job may directly depend on the agent's experience. Taken together, the success probability may be written as $f_{j}\left(e, \rho_{t}(\theta), t\right)$. This general formulation can capture learning by doing and human capital

\footnotetext{
${ }^{10}$ Robinson v. Small Business Administration, U.S.C.A.F.C. No. 06-3065, 5/4/06.
} 
accumulation: one possibility is that the productivity of an agent increases over time, $f_{j}(e, \rho, t+1)>f_{j}(e, \rho, t)$; or ability may increase with experience $\rho_{t+1}(\theta)>\rho_{t}(\theta)$. The model then can also encompass learning about the ability of an agent, if $\rho_{t}(\theta)$ is thought of as the expected ability given the information available ${ }^{11}$ Developing this more fully however is beyond the scope of our paper.

${ }^{11}$ Note that in our model we would have $\rho_{0}(\theta)=E[\theta]$ and $\rho_{t}(\theta)=\theta$. 


\section{Appendix}

\section{A Proofs}

\section{Proof of Lemma 1.}

$$
\begin{aligned}
\frac{d}{d \theta} \Pi_{h \theta}^{S B}(\bar{e}) & =f_{h \theta}(\bar{e}, \theta)-C_{h \theta}(\theta)=f_{h \theta}(\bar{e}, \theta)-\frac{f_{h}(\bar{e}, \theta) f_{h \theta}(\underline{e}, \theta)-f_{h}(\underline{e}, \theta) f_{h \theta}(\bar{e}, \theta)}{\left[f_{h}(\bar{e}, \theta)-f_{h}(\underline{e}, \theta)\right]^{2}} c \\
& >f_{h \theta}(\bar{e}, \theta)-\frac{f_{h}(\bar{e}, \theta) f_{h \theta}(\underline{e}, \theta)}{\left[f_{h}(\bar{e}, \theta)-f_{h}(\underline{e}, \theta)\right]^{2}} c>0,
\end{aligned}
$$

as $f_{h \theta}(\bar{e}, \theta) \geq f_{h \theta}(\underline{e}, \theta)$ (Assumption $\mathrm{SA}$ ) and $\left[f_{h}(\bar{e}, \theta)-f_{h}(\underline{e}, \theta)\right]^{2}>f_{h}(\bar{e}, \theta) c$ Condition 1). This shows Part (a). Part (b) follows immediately.

\section{Proof of Proposition 1.}

$$
\begin{aligned}
& \Pi_{h}^{S B}\left(\bar{e}, \theta^{F B}\right)-\Pi_{l}^{S B}(\bar{e})>0 \Leftrightarrow f_{h}\left(\bar{e}, \theta^{F B}\right)-C_{h}\left(\bar{e}, \theta^{F B}\right)>f_{l}(\bar{e})-C_{l}(\bar{e}) \\
& \Leftrightarrow C_{h}\left(\bar{e}, \theta^{F B}\right)<C_{l}(\bar{e}) \Leftrightarrow f_{h}\left(\bar{e}, \theta^{F B}\right)-f_{h}\left(\underline{e}, \theta^{F B}\right)>f_{l}(\bar{e})-f_{l}(\underline{e}) \\
& \Leftrightarrow f_{h}\left(\underline{e}, \theta^{F B}\right)<f_{l}(\underline{e}),
\end{aligned}
$$

using repeatedly $f_{h}\left(\bar{e}, \theta^{F B}\right)=f_{l}(\bar{e})$, as $\theta^{F B}=\hat{\theta}(\bar{e}, \bar{e})$. The resulting inequality $f_{h}\left(\underline{e}, \theta^{F B}\right)<f_{l}(\underline{e})$ implies that $\hat{\theta}(\bar{e}, \bar{e})<\hat{\theta}(\underline{e}, \underline{e})$. The rest follows because the profit difference is strictly increasing in $\theta$ (Lemma 1 ).

\section{Proof of Proposition 2.}

Part (a): Suppose that high effort was implemented in both jobs and denote by $\tilde{\theta}$ the ability level where expected profits in jobs $h$ and $l$ would be equalized: $\Pi_{h}^{S B}(\bar{e}, \tilde{\theta})=$ $\Pi_{l}^{S B}(\bar{e})$ (these are not the maximized second-best profit levels, as implementing high effort is not optimal in job $l$ and may not be in job $h$ either). From the proof of Proposition 1 we know that $\tilde{\theta}<\theta^{F B}=\hat{\theta}(\bar{e}, \bar{e})<\hat{\theta}(\underline{e}, \underline{e})$.

Denote by $\theta^{S B}$ the lowest threshold for assigning the agent to the high ability job. We now show that $\theta^{S B} \in(\tilde{\theta}, \hat{\theta}(\underline{e}, \underline{e})]$. Given that Condition 1 does not hold for job $l$, $\Pi_{l}^{S B}(\underline{e})=f_{l}(\underline{e})>\Pi_{l}^{S B}(\bar{e})=f_{l}(\bar{e})-C_{l}(\bar{e})$. Suppose first that Condition 1 does not hold for any $\theta \leq \hat{\theta}(\underline{e}, \underline{e})$ in job $h$ (but possibly for higher values). Then because $f_{h}(\underline{e}, \theta)<f_{l}(\underline{e})$ for $\theta<\hat{\theta}(\underline{e}, \underline{e})$ and $f_{h}(\underline{e}, \theta) \geq f_{l}(\underline{e})$ for $\theta \geq \hat{\theta}(\underline{e}, \underline{e})$ it follows immediately that $\theta^{S B}=\hat{\theta}(\underline{e}, \underline{e})$. Suppose now that Condition 1 holds for $\theta \geq \tilde{\theta}$ in job $h$ (and possibly also for lower values). Then, for these ability levels $\theta$ we have $\Pi_{h}^{S B}(\bar{e}, \theta)>\Pi_{h}^{S B}(\underline{e}, \theta)$ and $\Pi_{h \theta}^{S B}(\bar{e}, \theta)>0$ (Lemma 1. Because Condition 1 does not hold for job $l, \Pi_{l}^{S B}(\underline{e})>\Pi_{l}^{S B}(\bar{e})=\Pi_{h}^{S B}(\bar{e}, \tilde{\theta})$, and it follows that $\theta^{S B}>\tilde{\theta}$. Moreover, $\Pi_{h}^{S B}(\bar{e}, \hat{\theta}(\underline{e}, \underline{e}))>\Pi_{h}^{S B}(\underline{e}, \hat{\theta}(\underline{e}, \underline{e}))=\Pi_{l}^{S B}(\underline{e})$, so 
$\theta^{S B}<\hat{\theta}(\underline{e}, \underline{e})$. Finally, if Condition 1 holds only for some $\theta \in[\tilde{\theta}, \hat{\theta}(\underline{e}, \underline{e})]$, then a fortiori $\theta^{S B} \in(\tilde{\theta}, \hat{\theta}(\underline{e}, \underline{e})]$.

Part (b): To prove the if part, suppose that $f_{h}\left(\bar{e}, \theta^{F B}\right)-f_{l}(\underline{e})>C_{h}\left(\bar{e}, \theta^{F B}\right)$. Together with Condition 2 this implies that $f_{h}\left(\bar{e}, \theta^{F B}\right)-f_{h}\left(\underline{e}, \theta^{F B}\right)>C_{h}\left(\bar{e}, \theta^{F B}\right)$, so Condition 1 holds at $\theta^{F B}$ and the maximized second-best profit is $\Pi_{h}^{S B}\left(\bar{e}, \theta^{F B}\right)>\Pi_{l}^{S B}(\underline{e})$. By continuity, $\theta^{S B}<\theta^{F B}$.

To prove the only if part, suppose $\theta^{S B}<\theta^{F B}$. By definition at the second-best threshold $\Pi_{h}^{S B}\left(\bar{e}, \theta^{S B}\right) \geq f_{l}(\underline{e})$. The next steps show that $\Pi_{h}^{S B}(\bar{e}, \theta)$ is increasing in $\theta$ for $\theta \in\left[\theta^{S B}, \theta^{F B}\right]$, so that $\Pi_{h}^{S B}\left(\bar{e}, \theta^{F B}\right)>f_{l}(\underline{e})$, and that $f_{l}(\underline{e})>f_{h}\left(\underline{e}, \theta^{F B}\right)$. Together this then yields Condition 3. We first show the last part: Condition 2 implies that $\theta^{F B}<\hat{\theta}(\underline{e}, \underline{e})$ so $f_{l}(\underline{e})>f_{h}(\underline{e}, \theta)$ for $\theta \in\left[\theta^{S B}, \theta^{F B}\right]$. Next we prove that the profit strictly increases at $\theta^{S B}$. From the previous step and $\Pi_{h}^{S B}\left(\bar{e}, \theta^{S B}\right) \geq f_{l}(\underline{e})$ it follows that $\prod_{h}^{S B}\left(\bar{e}, \theta^{S B}\right)>f_{h}\left(\underline{e}, \theta^{S B}\right)$, which is equivalent to Condition 1 at $\theta^{S B}$. By Lemma 1 $\prod_{h \theta}^{S B}\left(\bar{e}, \theta^{S B}\right)>0$. Now we can show in the last step that the profit never falls back to or below $f_{l}\left(e_{l}\right)$ over the relevant range. By way of contradiction, suppose that there exist values $\theta_{n} \in\left(\theta^{S B}, \theta^{F B}\right]$ for which $\Pi_{h}^{S B}\left(\bar{e}, \theta_{n}\right)=f_{l}(\underline{e})$, and let $\theta_{1}$ denote the smallest of these. Because $\prod_{h}^{S B}\left(\bar{e}, \theta^{S B}\right) \geq f_{l}(\underline{e})$ and $\prod_{h \theta}^{S B}\left(\bar{e}, \theta^{S B}\right)>0$ it follows that $\prod_{h \theta}^{S B}\left(\bar{e}, \theta_{1}\right)<0$. This however implies that Condition 1 is violated at $\theta_{1}$, i.e. $\Pi_{h}^{S B}\left(\bar{e}, \theta_{1}\right)<f_{h}\left(\underline{e}, \theta_{1}\right)$, which leads to a contradiction because $f_{l}(\underline{e})>f_{h}\left(\underline{e}, \theta_{1}\right)$.

\section{Proof of Corollary 1 .}

Part 1 follows from Proposition 1 and Part 2 (a) follows from Proposition 2 (b) because $\theta^{F B}=\hat{\theta}(\bar{e}, \bar{e})$, and high effort is implemented for those placed in job $h$. Part 2 (b): When Condition 3 is violated $\theta^{F B} \leq \theta^{S B}$, where $\theta^{S B}$ denotes the lowest threshold for assigning the agent to the high ability job. Hence, two cases need to be considered. Suppose first that $\theta^{F B} \leq \theta^{S B}<\hat{\theta}(\underline{e}, \underline{e})$. Here $\Pi_{h}^{S B}(\underline{e}, \theta)=f_{h}(\underline{e}, \theta)<f_{l}(\underline{e})=\Pi_{l}^{S B}(\underline{e})$. So if the agent is assigned to job $h$ it must be that $e_{h}^{S B}(\theta)=\bar{e}$. The Peter Principle does not arise because $f_{h}(\bar{e}, \theta)>f_{l}(\bar{e})$. If the agent is assigned to job $l$ he exerts effort $\underline{e}$ and $f_{l}(\underline{e}, \theta)>f_{h}(\underline{e})$. Suppose now that $\theta^{S B} \geq \hat{\theta}(\underline{e}, \underline{e})$. Then the agent is always assigned to job $h$, either with effort $\underline{e}$ or $\bar{e}$, and we have $f_{h}(e, \theta) \geq f_{l}(e)$ for $e \in\{\underline{e}, \bar{e}\}$.

\section{B Continuous effort model}

\section{Model}

Expected outputs in jobs $l$ and $h$ are $f_{l}(e, \theta)=\alpha e$ and $f_{h}(e, \theta)=\max \{\alpha e \theta-k, 0\}$, respectively. The cost of effort is $c(e)=e^{2} / 2$. Below we use the following parametrization to guarantee proper probability distribution functions (i.e. $\left.f_{j}(e, \theta) \in[0,1]\right)$ and to avoid 
corner solutions: $\theta \in\left[\frac{1}{2}, 2\right], e \in[0,1], \alpha=1 / 2$, and $0<k<1 / 16$. This implies that $f_{h}(e, \theta) \in[0,3 / 4]$ and $f_{l}(e, \theta) \in[0,1-k]$.

\section{First Best}

The efficient effort level given $\theta$ solves $\max _{e} f_{j}(e, \theta)-c(e)$. For job $l$ this yields $e_{l}^{F B}=\alpha=1 / 2$ and for job $h$ we have $e_{h}^{F B}(\theta)=\alpha \theta=\theta / 2$. Hence, expected profits are: $\Pi_{l}^{F B}=\frac{\alpha^{2}}{2}$ and $\Pi_{h}^{F B}(\theta)=\frac{\alpha^{2} \theta^{2}}{2}-k$. Setting profits equal and solving for $\theta$ gives us the efficient threshold: $\theta^{F B} \equiv \sqrt{\frac{1+2 k}{\alpha^{2}}}=\sqrt{1+8 k}$.

\section{Second Best}

To implement effort $e$ in job $j$ the wage after success must be set at $\bar{w}_{j}(e, \theta)=\frac{c_{e}(e)}{f_{j e}(e, \theta)}$, where subscript $e$ denotes the partial derivative with respect to effort. This yields $\bar{w}_{l}(e)=\frac{e}{\alpha}=2 e$ and $\bar{w}_{h}(e, \theta)=\frac{e}{\alpha \theta}=2 e / \theta$. Denote the expected cost of implementing effort in job $j$ by $C_{j}(e, \theta)=f_{j}(e, \theta) \bar{w}_{j}(e, \theta)$.

Maximizing the principal's expected profit $f_{j}(e, \theta)-C_{j}(e, \theta)$ over $e$ gives the secondbest effort level for a type- $\theta$ agent. In job $h$ this yields $e_{h}^{S B}(\theta)=\frac{\alpha^{2} \theta^{2}+k}{2 \alpha \theta}=\frac{\theta^{2}+4 k}{4 \theta}$ and in job $l$ we have $e_{l}^{S B}=\alpha / 2=1 / 4$. These are exactly half the efficient effort levels if $k=0$; otherwise, $e_{h}^{S B}(\theta)=\frac{e_{l}^{F B}(\theta)}{2}+\frac{k}{\theta}$. Expected profits are:

$$
\begin{aligned}
\Pi_{l} & =f_{l}\left(e_{l}^{S B}\right)-C_{l}\left(e_{l}^{S B}\right)=\frac{\alpha^{2}}{4}=\frac{1}{16} \\
\Pi_{h}(\theta) & =f_{h}\left(e_{h}^{S B}(\theta), \theta\right)-C_{h}\left(e_{h}^{S B}(\theta), \theta\right)=\frac{\left(\alpha^{2} \theta^{2}-k\right)^{2}}{4 \alpha^{2} \theta^{2}}=\frac{\left(\theta^{2}-4 k\right)^{2}}{16 \theta^{2}} .
\end{aligned}
$$

Subtracting gives

$$
\Pi_{l}-\Pi_{h}(\theta)=\frac{\left[k-\alpha^{2} \theta(1+\theta)\right]\left[k+\alpha^{2} \theta(1-\theta)\right]}{4 \alpha^{2} \theta}=\frac{[4 k-\theta(1+\theta)][4 k+\theta(1-\theta)]}{16 \theta^{2}} .
$$

Setting this equal to zero, we obtain the second-best threshold for assigning an agent to job $h: \theta^{S B} \equiv \frac{1+\sqrt{1+16 k}}{2}$. For the range of parameter values allowed, there are no corner solutions; and the other roots of the equation above are irrelevant.

We now prove formally the remaining results discussed in the text:

Promotion threshold $\theta^{S B}<\theta^{F B}$ FOR $k>0$ :

By way of contradiction, suppose $\theta^{F B} \leq \theta^{S B} \quad \Leftrightarrow \quad \sqrt{1+8 k} \leq \frac{1+\sqrt{1+16 k}}{2} \Rightarrow 2 \sqrt{1+8 k} \leq$ $1+\sqrt{1+16 k} \Rightarrow 4+32 k>2+2 \sqrt{1+16 k}+16 k \Rightarrow 1+16 k+64 k^{2} \leq 1+16 k$, yielding a contradiction for $k>0$.

\section{EXPECTED OUTPUT:}

For an agent placed in job $h$, the expected output is higher than it would have been if he 
were instead assigned to job $l$ (with the second-best effort level for the respective job). At $\theta^{S B}$ there is an upward jump in expected output:

$$
f_{h}\left(e_{h}^{S B}\left(\theta^{S B}\right), \theta^{S B}\right)-f_{l}\left(e_{l}^{S B}\right)=\frac{\alpha\left(\sqrt{\alpha^{2}+4 k}-\alpha\right)}{4}>0 .
$$

This difference is increasing in $\theta$, so the relation also holds for all $\theta>\theta^{S B}$ :

$$
\begin{gathered}
f_{h}\left(e_{h}^{S B}(\theta), \theta\right)-f_{l}\left(e_{l}^{S B}\right)=\frac{\alpha^{2}\left(\theta^{2}-1\right)-k}{2}=\frac{\theta^{2}-1-4 k}{8}, \\
\frac{\partial}{\partial \theta}\left\{f_{h}\left(e_{h}^{S B}(\theta), \theta\right)-f_{l}\left(e_{l}^{S B}\right)\right\}=\alpha^{2} \theta>0 .
\end{gathered}
$$

\section{The Peter PRINCIPLE:}

Keeping effort constant at the second-best level for job $h$, the expected output for an agent with ability $\theta^{S B}$ placed in job $h$ is lower than it would have been if he were instead assigned to job $l$ :

$$
f_{h}\left(e_{h}^{S B}\left(\theta^{S B}\right), \theta^{S B}\right)-f_{l}\left(e_{h}^{S B}\left(\theta^{S B}\right)\right)=\frac{-8 k \alpha}{8\left(\alpha+\sqrt{\alpha^{2}+4 k}\right)}=\frac{-32 k}{32(1+\sqrt{1+16 k})}<0 .
$$

EFFORT $e_{h}^{S B}(\theta)>e_{l}^{S B}$ FOR $\theta>\theta^{S B}$ :

At $\theta^{S B}$ there is an upward jump in effort: $e_{h}^{S B}\left(\theta^{S B}\right)-e_{l}^{S B}=\frac{2 k}{\alpha+\sqrt{\alpha^{2}+4 k}}=\frac{4 k}{1+\sqrt{1+16 k}}$. The effort in job $h$ is increasing in $\theta: \frac{d}{d \theta} e_{h}^{S B}(\theta)=\frac{1}{4}-\frac{k}{\theta^{2}}>0$ for the admissible parameter values.

\section{EXPECTED EARNINGS:}

For an agent assigned to job $h$, expected earnings are higher than they would have been when remaining in job $l$. We prove this indirectly by combining the result that the success probability is higher (see above) and that the wage after success is higher, as we now show. At $\theta^{S B}$ there is an upward jump in the wage after success: $\bar{w}_{h}\left(e_{h}^{S B}\left(\theta^{S B}\right), \theta^{S B}\right)-$ $\bar{w}_{l}\left(e_{l}^{S B}\right)=\frac{8 k}{(1+\sqrt{1+8 k})^{2}}$. The difference in wages following success across jobs is increasing in $\theta$, so this is true for all $\theta>\theta^{S B}$ :

$$
\begin{gathered}
\bar{w}_{h}\left(e_{h}^{S B}(\theta), \theta\right)-\bar{w}_{l}\left(e_{l}^{S B}\right)=\frac{\theta^{2}(\theta-1)-16 k}{16 \theta^{2}}, \\
\frac{\partial}{\partial \theta}\left\{\bar{w}_{h}\left(e_{h}^{S B}(\theta), \theta\right)-\bar{w}_{l}\left(e_{l}^{S B}\right)\right\}=\frac{\theta^{4}+16 k}{8 \theta^{3}}>0 .
\end{gathered}
$$

\section{EXPECTED UTILITY:}

The expected utility close to the threshold $\theta^{S B}$ is lower in job $h$ than if the agent could remain in job $l: E U_{h}\left(e_{h}^{S B}\left(\theta^{S B}\right), \theta^{S B}\right)-E U_{l}\left(e_{l}^{S B}\right)=-128 k^{2}$. The difference in expected utilities across jobs is increasing in $\theta$ :

$$
\frac{\partial}{\partial \theta}\left\{E U_{h}\left(e_{h}^{S B}(\theta), \theta\right)-E U_{l}\left(e_{l}^{S B}\right)\right\}=\frac{\theta^{4}+48 k^{2}}{16 \theta^{3}}>0 .
$$




\section{References}

Auriol, E., And R. Renault (2007): "Status and Incentives," RAND Journal of Economics, forthcoming.

Baker, G., R. Gibbons, and K. J. Murphy (1994): "Subjective Performance Measures in Optimal Incentive Contracts," Quarterly Journal of Economics, 109(4), 11251156.

Baker, G., M. GibBs, And B. Holmstrom (1994a): "The Internal Economics of the Firm: Evidence from Personnel Data," Quarterly Journal of Economics, 109, 881-919.

(1994b): "The Wage Policy of a Firm," Quarterly Journal of Economics, 109, 921-955.

Baker, G. P., M. C. Jensen, and K. J. Murphy (1988): "Compensation and Incentives: Practice Vs. Theory," Journal of Finance, 43(3), 593-616.

Baliga, S., And T. Sjöström (2001): "Optimal Design of Peer Review and SelfAssessment Schemes," RAND Journal of Economics, 32(1), 27-51.

Bernhardt, D. (1995): "Strategic Promotion and Compensation," Review of Economic Studies, 62(2), 315-39.

Calvo, G. A., and S. Wellisz (1979): "Hierarchy, Ability, and Income Distribution," Journal of Political Economy, 87(5), 991-1010.

Carmichael, H. L. (1988): "Incentives in Academics: Why Is There Tenure?," Journal of Political Economy, 96(3), 453-72.

CARrillo, J. D. (2003): "Job Assignments as a Screening Device," International Journal of Industrial Organization, 21(6), 881-905.

Chiappori, P.-A., B. Salanie, and J. Valentin (1999): "Early Starters versus Late Beginners," Journal of Political Economy, 107(4), 731-760.

Cooper, C. L., and J. Marshall (1976): "Occupational Sources of Stress: A Review of the Literature Relating to Coronary Heart Disease and Mental Ill Health," Journal of Occupational Psychology, 49, 11-28.

Demougin, D., And C. Fluet (1998): "Mechanism Sufficient Statistic in the RiskNeutral Agency Problem," Journal of Institutional and Theoretical Economics, 127(4), 622-639. 
Erskine, J., And A. Brook (1971): "Report on a Two Year Experiment in CoOperation Between an Occupational Physician and a Consultant Psychiatrist," Occupational Medecine, 21, 53-56.

Fairburn, J. A., And J. M. Malcomson (2001): "Performance, Promotion, and the Peter Principle," The Review of Economic Studies, 68(1), 45-66.

FARIA, J. R. (2000): "An Economic Analysis of the Peter and Dilbert Principles," Working Paper Series 101, University of Technology, Sydney.

Friebel, G., and M. Raith (2004): "Abuse of Authority and Hierarchical Communication," RAND Journal of Economics, 35(2), 224-244.

Gibbons, M. R., and M. Waldman (2006): "Enriching a Theory of Wage and Promotion Dynamics Inside Firms," Journal of Labor Economics, 24(1), 59-107.

Gibbons, R., and M. Waldman (1999a): "Careers in Organizations: Theory and Evidence," in Handbook of Labor Economics, ed. by O. Ashenfelter, and D. Card, vol. 3B, chap. 36, pp. 2373-2437. Elsevier, Amsterdam.

(1999b): "A Theory Of Wage and Promotion Dynamics Inside Firms," The Quarterly Journal of Economics, 114(4), 1321-1358.

GibBs, M., And W. Hendricks (2004): "Do Formal Salary Systems Really Matter?," Industrial \& Labor Relations Review, 58(1), 71-93.

Grossman, S. J., And O. D. Hart (1983): "An Analysis of the Principal-Agent Problem," Econometrica, 51(1), 7-45.

IsHIDA, J. (2006): "Optimal Promotion Policies with the Looking-Glass Effect," Journal of Labor Economics, 24, 857-877.

JEwitT, I. (2006): "Information Order in Decision and Agency Problems," mimeo, University of Oxford.

Kim, S. K. (1995): "Efficiency of an Information System in an Agency Model," Econometrica, 63(1), 89-102.

Kwon, I. (2006): "Incentives, Wages, and Promotions: Theory and Evidence," RAND Journal of Economics, 37(1), 100-120.

Lazear, E. P. (2004): "The Peter Principle: A Theory of Decline," Journal of Political Economy, 112(1), 141-163. 
Lazear, E. P., And S. Rosen (1981): "Rank-Order Tournaments as Optimum Labor Contracts," Journal of Political Economy, 89(5), 841-864.

Lin, M.-J. (2005): "Opening the Black Box: The Internal Labor Markets of Company X," Industrial Relations, 44(4), 659-706.

MacLeod, W. B., and J. M. Malcomson (1988): "Reputation and Hierarchy in Dynamic Models of Employment," Journal of Political Economy, 96(4), 832-54.

Malcomson, J. M. (1984): "Work Incentives, Hierarchy, and Internal Labor Markets," Journal of Political Economy, 92(3), 486-507.

Maskin, E., Y. Qian, And C. Xu (2000): "Incentives, Information, and Organizational Form," Review of Economic Studies, 67(2), 359-378.

Meyer, M. A. (1991): "Learning from Coarse Information: Biased Contests and Career Profiles," Review of Economic Studies, 58(1), 15-41.

Murphy, L. R. (1995): “Occupational Stress Management: Current Status and Future Direction," Trends in Organizational Behavior, 2, 1-14.

NAFZIGER, J. (2007): “Job Assignments, Intrinsic Motivation and Extrinsic Incentives," mimeo, Université Libre de Bruxelles.

O'Flaherty, B., and A. Siow (1992): "On the Job Screening, up or out Rules, and Firm Growth," Canadian Journal of Economics, 25(2), 346-68.

Ortega, J. (2003): "Power in the Firm and Managerial Career Concerns," Journal of Economics and Management Strategy, 12(1), 1-29.

Peter, L. J., And R. Hull (1969): The Peter Principle: Why Things Always Go Wrong. William Morrow \& Co. Inc, New York.

Prendergast, C. (1993): "The Role of Promotion in Inducing Specific Human Capital Acquisition," Quarterly Journal of Economics, 108(2), 523-534.

Prescott, E. C., And M. Visscher (1980): "Organization Capital," Journal of Political Economy, 88(3), 446-461.

Ricart i Costa, J. E. (1988): “Managerial Task Assignment and Promotions," Econometrica, 56(2), 449-66.

Robbins, E. H., And B. Sarath (1998): "Ranking Agencies under Moral Hazard," Economic Theory, 11, 129-155. 
Rosen, S. (1982): "Authority, control, and the distribution of earnings," Bell Journal of Economics, 13(2), 311-323.

(1986): "Prizes and Incentives in Elimination Tournaments," American Economic Review, 76(4), 701-715.

Seltzer, A., And D. T. Merrett (2000): "Personnel Policies at the Union Bank of Australia: Evidence from the 1888-1900 Entry Cohorts," Journal of Labor Economics, 18(4), 573-613.

Treble, J., E. Van Gameren, S. Bridges, and T. Barmby (2001): "The Internal Economics of the Firm: Further Evidence from Personnel Data," Labour Economics, $8(5), 531-552$.

VAlsecCHI, I. (2003): "Job Assignment and Bandit Problems," International Journal of Manpower, 24(7), 844-866.

Waldman, M. (1984a): "Job Assignments, Signalling, and Efficiency," RAND Journal of Economics, 15(2), 255-267.

(1984b): "Worker Allocation, Hierarchies and the Wage Distribution," Review of Economic Studies, 51(1), 95-109. 